\title{
Role of Periodontal Disease on Systemic Health
}

\author{
Minic I* \\ Department of Periodontology and Oral medicine, Medical Faculty, University of Nis, Serbia
}

${ }^{*}$ Corresponding author: Ivan Minic, Department of Periodontology and Oral medicine, Medical Faculty, University of Nis, Serbia, Tel: +381643004883; E-mail: ivanminnic@yahoo.com

Received date: November 15, 2018; Accepted date: November 19, 2018; Published date: November 21,2018

Citation: Minic I (2018) Role of Periodontal Disease on Systemic Health. Arch Med e-103

Copyright: (C2018 Minic I. This is an open-access article distributed under the terms of the Creative Commons Attribution License, which permits unrestricted use, distribution, and reproduction in any medium, provided the original author and source are credited

\section{Editorial}

Periodontal medicine is a term used for different purposes in different parts of the world. In certain countries, it relates to the study of the dynamic relationship between periodontal diseases and systemic conditions [1]. During the past 15 years, a large body of literature has identified oral/periodontal infection and inflammation as a risk factor for the development and/or severity of certain systemic diseases and disorders. Many studies have been focused on the influence of periodontal disease on diabetes mellitus, cardiovascular disease, adverse birth outcomes and respiratory diseases. Other associations have been reported (e.g. dementia, chronic kidney disease and certain forms of cancer), but the literature on these topics is not robust [2-4].

Parodontopathy is a chronic inflammatory disease of tooth tissue caused by dental plaque bacteria. The presence of bacteria alone is not sufficient for the development of periodontal disease. The most frequently identified periodontal pathogens include three microaerophilic species (Actinobacillus actinomycetemcomitans, Campylobacter rectus, and Eikenella corrodens) and seven anaerobic species (Porphyromonas gingivalis, Bacteroides forsythus, Treponema denticola, Prevotella intermedia, Fusobacterium nucleatum, Eubacterium, and spirochetes) [5].

Uncontrolled severe periodontitis caused by periodontal pathogens represents a major infectious threat to the entire body, since released toxins and other inflammatory mediators can reach and affect distant organs. During the local inflammatory reaction, inflammatory mediators are produced. The most significant is prostaglandin E2 (PGE2), interleukin-1 $\beta$ (IL-1 $\beta$ ), interleukin 6 (IL-6) and tumour necrosis factor alpha (TNF- $\alpha$ ). Pro-inflammatory cytokines have been distinguished as inflammatory mediators whose production intensity is an indicator of the periodontium tissue destruction activity [6]. Patients with periodontal disease have been shown to have elevated values of these pro-inflammatory cytokines in the gingival fluid compared to respondents with healthy periodontal tissue [7].

Due to the increased permeability of periodontium blood vessels, which occurs as a result of inflammation, proinflammatory cytokines have the ability to penetrate the systemic circulation. These inflammatory mediators can cause many health problems and illnesses. It is mostly described effect of periodontal disease is in the etiology of diabetes mellitus, cardiovascular diseases, preterm-born women [8-9].

\section{Diabetes Mellitus and Periodontal Disease}

Like other complications of diabetes, gum disease is associated with disease control. Patients with an inadequate blood sugar control level are more likely to suffer from periodontal disease in a more serious form [10]. In the onset of the stage of parodontium disease, the disease was accompanied by a large loss of teeth. In children with insulin-dependent type of diabetes (type I) there is also a risk of gum disease [11]. The thickening of the walls of peripheral blood vessels (capillaries) is the main complication of diabetes, which significantly increases the risk of gum disease. Blood vessels bring oxygen and nutrients to the mouth at the same time by referring to decay products from the same [12]. The reduced passage of nutrients and oxygen to the tissue, and on the other hand, the reduction in the elimination of harmful substances reduces the resistance of gums and alveolar bones from infections. Thanks to interdisciplinary research, every strain and type of microorganisms that cause disease in the mouth are known today. Many important metabolites are glucose-a diabeticrelated diet [13].

\section{Parodontopathy as a Risk Factor for Premature Birth}

Three hypotheses that can explain the relationship between periodontal infection and premature labor are:

- Periodontal pathogens causing direct contamination of the fetoplacental unit.

- Lipopolysaccharide, bacterial endotoxin, found in infected periodontium, is released and affects the fetoplacental unit through the blood.

- Inflammatory mediators from the infected periodontal reservoir can cause problems in the fetoplacental unit [14-16].

More research is needed to prove the impact of periodontal disease on systemic health. The results of numerous studies and 
the development of periodontal medicine have led to productive cooperation with colleagues in medicine, and discovered many new evidences that suggest that the oral cavity is an integral part of the human body, and that systemic health must include oral and periodontal health.

\section{Conclusion}

Only the treatment and prevention of periodontal disease are becoming increasingly important factors in maintaining oral health, but also in maintaining the health of the whole organism

\section{References}

1. Otomo-Corgel J, Merim RL (2007) Periodontal disease and systemic health-What you and your patients need to know? South Med J 100: 686-691.

2. Lakio L, Pussinen PJ, Jauhiainen M, Asikainen S (2002) Actinobacillus actinomycetemcomitans LPS induces macrophagederived foam cell formation. J Dent Res 81: 126-131.

3. Loeshe W, Karapetov F, Pohl A, Pohl C, Kocher T (2000) Plasma lipid and blood glucose levels in patients with destructive periodontal disease. J Clin Periodontol 27: 537-541.

4. Kiechl S, Egger G, Mayr M (2001) Chronic infections and the risk of carotid atherosclerosis: prospective results from a large population study. Circulation 103: 1064-1070.

5. Buhlin K, Mantyla P, Paju S (2001) Periodontitis is associated with angiographically verified coronary artery disease. J Clin Periodontol 38: 1007-1014.

6. Pradeep AR, Hadge P, Arjun Raju P, Shetty SR, Shareef K, et al. (2010) Periodontitis as a risk factor for cerebrovascular accident: a case-control study in the Indian population. J Periodontal Res 45: 223-228.
7. Deo V, Bhongade ML, Ansari S, Chavan RS (2009) Periodontitis as a potential risk factor for chronic obstructive pulmonary disease: $A$ retrospective study. Indian J Dent Res 20: 466-470.

8. Canacki V, Canacki CF, Yildrim A, Ingec M, Eltas A, et al. (2007) Periodontal disease increases the risk of severe pre-eclampsia among pregnant women. J Clin Periodontol 34: 639-645.

9. Gulati M, Anand V, Jain N, Anand B, Bahuguna R, et al. Essentials of periodontal medicine in preventive medicine. Int J Prev Med 4: 988-994.

10. Al-Zahrani MS, Bissada NF, Borawskit EA (2003) Obesity and periodontal disease in young, middle-aged, and older adults. J Periodontal 74: 610-615.

11. American Diabetes Association Economic costs of diabetes in the US in 2007. Diabetes Care. 31: 596-615.

12. Bahia LR, Araujo DV, Schaan BD, Dib SA, Negrato CA, et al. (2011) The costs of type 2 diabetes mellitus outpatient care in the Brazilian public health system. Value Health. 14: S137-S140.

13. Demmer RT, Jacobs Jr DR, Desvarieux M (2008) Periodontal disease and incident type 2 diabetes: results from the first national health and nutrition examination survey and its epidemiologic follow-up study. Diabetes Care 31: 1373-1379.

14. Menon R, Torloni MR, Voltolini C, Torricelli M, Merialdi M, et al. (2011) Biomarkers of spontaneous preterm birth: An overview of the literature in the last four decades. Reproductive Sci 18: 1046-1070.

15. Marcdante KF, Kligman RM (2011) Fetus and newborn. Essentials of pediatrics. 6th edn, Philadelphia, USA.

16. Blencowe $\mathrm{H}$, Cousens $\mathrm{S}$, Oestergaard $\mathrm{M}$, Chou $\mathrm{D}$, Moller $\mathrm{AB}$, et al. (2012) National, regional and worldwide estimates of preterm birth. The Lancet 379: 2162-2172. 